\title{
EFFECT OF THREE COMMERCIAL EXTENDERS ON SPERM MOTILITY AND FERTILITY IN LIQUID RAM SEMEN STORED AT $15^{\circ} \mathrm{C}$ OR $5^{\circ} \mathrm{C}$
}

\author{
Ander ARANDo ${ }^{1 *}$, Juan Vicente Delgado ${ }^{1}$, José Manuel LeÓN ${ }^{2}$, Sergio Nogales ${ }^{1}$, \\ Francisco Javier NAVAS-GONZÁLEZ ${ }^{1}$, María Gabriela PIZARRO ${ }^{1}$ and \\ Carlos Carmelo PÉREZ-MARÍN ${ }^{3}$ \\ ${ }^{1}$ Department of Genetics, University of Cordoba, Campus de Rabanales, Ctra. Madrid- \\ Cadiz km 396, 14014 Cordoba, Spain; ${ }^{2}$ Diputacion de Cordoba, Cordoba, Spain; \\ ${ }^{3}$ Department of Animal Medicine and Surgery, University of Cordoba, Cordoba, Spain
}

(Received 19 January 2019; accepted 2 May 2019)

The effect of different extenders on sperm motility and fertility was evaluated during liquid storage of ram semen at $5{ }^{\circ} \mathrm{C}$ and $15^{\circ} \mathrm{C}$. The semen was collected, pooled and diluted in three commercial extenders: Inra $96^{\circledR}$ (INRA) based on skimmed milk, Biladyl ${ }^{\circledR}$ A fraction (BIL) based on egg yolk, and Ovixcell ${ }^{\circledR}$ (OVIX) based on soybean lecithin. Then, sperm motility was evaluated at $0,6,24$, 48,72 and $96 \mathrm{~h}$. In order to evaluate fertility, samples stored at $15^{\circ} \mathrm{C}$ were used after dilution in INRA and OVIX. Results showed that progressive motility was significantly higher up to $72 \mathrm{~h}$ of storage in sperm samples maintained at $5^{\circ} \mathrm{C}$ in comparison with $15^{\circ} \mathrm{C}$, similarly for each tested diluent. When samples were stored at $5^{\circ} \mathrm{C}$ in OVIX, kinematic parameters such as velocity (except curvilinear velocity, VCL), trajectory [linearity (LIN), straightness (STR), wobble (WOB)], amplitude of lateral head displacement $(\mathrm{ALH})$ and beat/cross frequency $(\mathrm{BCF})$ were higher than in INRA and BIL. No significant differences in pregnancy rate were detected between INRA (62.6\%) and OVIX (58.9\%). In conclusion, liquid storage at $5{ }^{\circ} \mathrm{C}$ with OVIX extender is an interesting option since non-animal components are used, and this extender offers similar in vitro and in vivo efficacy as other extenders containing animal components.

Key words: Fertility, liquid storage, ram sperm, extender, CASA

The Segureña breed is one of the most important indigenous Spanish meat sheep breeds, located in the highlands of Granada, Sierra de Segura and Las Villas, one of the poorest areas of Europe. This breed is reared under extensive and semi-extensive conditions due to its high rusticity and adaptability, and allows to maintain the balance between environmental and social sustainability of the region (Lupi et al., 2015).

\footnotetext{
*Corresponding author; E-mail: anderarando@hotmail.com; Phone: 0034 (62) 645-1265
} 
Artificial insemination (AI) is an essential tool within the official genetic improvement programme of the Segureña breed, as it enables the connection between flocks and accelerates genetic progress. However, variable fertility rates, low economic returns and rapid loss of sperm quality during storage are important handicaps for the routine use of this technique (Mata-Campuzano et al., 2014). The successful application of AI in the ovine species is influenced by many factors such as the complex anatomy of the ovine cervix (Halbert et al., 1990), semen preservation, livestock management, farming system, health, physiological status of the sheep, semen deposition technique, environmental factors, human factor, sperm concentration or extender composition (Anel et al., 2005), among others. However, changes in sperm quality along this process have been reported to decrease fertility as preservation time increases (López et al., 1999).

With regard to extender composition, which is one of the main factors involved in the successful liquid storage of ram sperm, Tris-based media containing egg yolk or milk as protectants for ram spermatozoa during liquid storage are widely used (Kasimanickam et al., 2011). Egg yolk is a non-penetrating cryoprotectant that avoids or reduces the cold shock of sperm cells during the drop of temperature, preserving sperm motility, acrosome integrity and the mitochondrial membrane. These properties are attributed to the low-density lipoproteins (LDL) present in egg yolk (Tabaréz et al., 2017). However, milk proteins act as a buffer against $\mathrm{pH}$ changes, as a chelator against heavy metals, and they also partially protect the membrane (Salamon and Maxwell, 2000). Although extenders based on egg yolk or skimmed milk provide beneficial effects on sperm quality during liquid storage and cryopreservation, they are animal-derived products and present a potential sanitary risk since they can be vectors for disease transmission and microbial contamination that might favour the production of endotoxins (Toker et al., 2016). In the past few years, other substances of non-animal origin, such as plant-derived lecithins, have been used for sperm preservation to avoid such problems, with soybean lecithin being one of the most widely used ones (Chelucci et al., 2015).

Therefore, the aim of the present study was to compare the in vitro effects of three commercial extenders containing animal-derived (skimmed milk or egg yolk) or plant-derived (soybean lecithin) components during liquid storage of ram semen at different temperatures $\left(15^{\circ} \mathrm{C}\right.$ or $\left.5{ }^{\circ} \mathrm{C}\right)$ for $96 \mathrm{~h}$. We also determined the fertility of liquid ram sperm stored at $15^{\circ} \mathrm{C}$, diluted in extenders containing proteins of animal and non-animal origin. 
ARANDO et al

\section{Materials and methods}

Animals, semen collection, preparation and assessment

Five German Mutton Merino (Merino Fleischschaf) and nine Segureña rams (3-5 years of age) of proven fertility from the Diputacion de Cordoba and Granada (Spain), respectively, were included in the present study.

Semen was collected during the breeding season (October-February) using an artificial vagina. Animals were housed individually and fed a commercial concentrate $(0.5 \mathrm{~kg})$, with ad libitum access to alfalfa hay, water and mineral supplementation blocks. Ejaculates were placed into tubes and immersed in a water bath at $37{ }^{\circ} \mathrm{C}$. Volume (by graduated tubes), sperm concentration (Accurread, IMV technologies, France) and mass motility (from 1 to 5 ; 40× magnification; Olympus, Tokyo, Japan) were determined for each semen sample. The inclusion criteria for ejaculates were as follows: volume $\geq 0.5 \mathrm{ml}$, sperm concentration $\geq 3,000 \times 10^{6} \mathrm{sperm} / \mathrm{ml}$, and mass motility $\geq 4$. Animal management conformed to the relevant regulations of the European Union (Directive 2010/63/EU) and the transposition of animals to the Spanish law (RD 53/2013).

Three commercial extenders: Inra $96^{\circledR}$ (INRA, IMV technologies, France) based on skimmed milk, Biladyl ${ }^{\circledR}$ A fraction (BIL, Minitube Iberica S.L, Tarragona, Spain) based on egg yolk, and Ovixcell ${ }^{\circledR}$ (OVIX, IMV technologies, France) based on soybean lecithin were used in this study.

After individual evaluation, ejaculates were split in three aliquots, diluted at 1:2 with different extenders (INRA, OVIX, and BIL) and placed in a water bath at $37{ }^{\circ} \mathrm{C}$. Subsequently, to avoid individual variation, the aliquots containing the same extender were pooled and diluted to a final concentration of $400 \times 10^{6}$ sperm $/ \mathrm{ml}$. After dilution, sperm samples were again split in half and stored at $5^{\circ} \mathrm{C}$ and $15^{\circ} \mathrm{C}$. Motility was evaluated at $0,6,24,48,72$ and $96 \mathrm{~h}$ after collection. The in vitro experiment was replicated 6 times in German Mutton Merino rams, using a total of 30 ejaculates.

Motility analysis was performed using software ISAS v.1.2 (Integrated Semen Analyser System, Proiser, Valencia, Spain). Sperm aliquots were diluted to a final concentration of $25 \times 10^{6}$ sperm $/ \mathrm{ml}$ with the same extender used for chilling. After dilution, sperm samples were warmed at $37^{\circ} \mathrm{C}$ for $10 \mathrm{~min}$. A volume of $5 \mu \mathrm{l}$ was placed on a slide and covered with a $22 \times 22 \mathrm{~mm}$ coverslip. Four fields and a minimum of 500 spermatozoa were randomly captured at $100 \times$ magnification. Total motility (TM, \%), progressive motility (PM, \%), curvilinear velocity (VCL, $\mu \mathrm{m} / \mathrm{sec}$ ), straight-line velocity (VSL, $\mu \mathrm{m} / \mathrm{sec}$ ), average path velocity (VAP, $\mu \mathrm{m} / \mathrm{sec}$ ), linearity (LIN, \%), straightness (STR, \%), wobble (WOB, \%), amplitude of lateral head displacement (ALH, $\mu \mathrm{m}$ ), and beat/cross frequency $(\mathrm{BCF}, \mathrm{Hz})$ were determined. Spermatozoa set-up was established for the head area between 15 and $70 \mu \mathrm{m}^{2}$, VAP $>10 \mu \mathrm{m} / \mathrm{sec}$ for motile cells, and sperm were considered to be linearly motile when they deviated $<75 \%$ from a straight line. 


\section{Artificial insemination trial}

Two Merino farms located in Southern Spain (Cordoba, Spain) were chosen for this study. A total of 180 sheep and 9 tested Segureña (3-5 years old) rams were involved. Females were randomly assigned to two different groups and inseminated with cooled sperm samples diluted in INRA (skimmed milk extender) or OVIX (soybean lecithin extender). They were chosen considering the best progressive motility and velocity values obtained during the in vitro experiment. The ewes involved in this trial ranged between 2 and 5 years of age and the lambing to insemination interval was extended from 64 to 98 days. Sheep were synchronised using an intravaginal device impregnated with $60 \mathrm{mg}$ medroxyprogesterone acetate (Esponjavet ${ }^{\circledR}$, HIPRA), and received a dose of $400 \mathrm{IU}$ eCG (Oviser ${ }^{\circledR}$, HIPRA) intramuscularly when the sponges were withdrawn. For timefixed AI, cooled $\left(15^{\circ} \mathrm{C}\right)$ sperm samples were deposited vaginally. The sperm samples were prepared and pooled as described in the in vitro trial. This method was selected as it was the most efficient method that yields acceptable pregnancy rates (Anel et al., 2006). Sperm doses were used around $6 \mathrm{~h}$ after collection, and females were inseminated around $55 \pm 1 \mathrm{~h}$ after sponge removal, with $400 \times 10^{6}$ spermatozoa per ewe. These animals were reared in extensive production systems and pregnancy was determined by external ultrasonography (Agroscan A8, ECM, France) at 42 days after insemination.

\section{Statistical analysis}

The SPSS 22.0 software (Chicago, IL, USA) was used for the statistical analysis. Normality was tested using the Kolmogorov-Smirnov test. As the data exhibited a non-normal distribution (except ALH and BCF traits), arcsin and $\ln$ transformation was carried out for percentages and continuous data, respectively. Repeated-measure analysis was used to test the effect of storage time $(0,6,24$, 48, 72 and $96 \mathrm{~h}$ ), extender (INRA, OVIX, BIL) and their interactions in motility and kinematic parameters. An ANOVA analysis was performed to determine the effect of temperature, for each time and within each extender, using temperature variation as a factor. Fertility was analysed using logistic regression, and farm and extender factors were included in the model. When significant differences $(\mathrm{P}<0.05)$ were detected, a LSD post-hoc test was carried out. The results are shown as mean $\pm \mathrm{SD}$.

\section{Results}

\section{Effect of extender and storage time at $5{ }^{\circ} \mathrm{C}$}

The effect of extender, storage time at $5{ }^{\circ} \mathrm{C}$ and their interactions were analysed. Extender $\times$ storage time interactions were statistically significant $(\mathrm{P}<$ 0.05 ) for TM, VCL, LIN, and WOB. In contrast, no interactions were observed 
for PM, VSL, STR, VAP, ALH, and BCF. Therefore, these factors were studied as the main effect. Figure 1 shows the TM and PM values throughout the 96-h storage time. Table 1 shows the results obtained for the other variables.
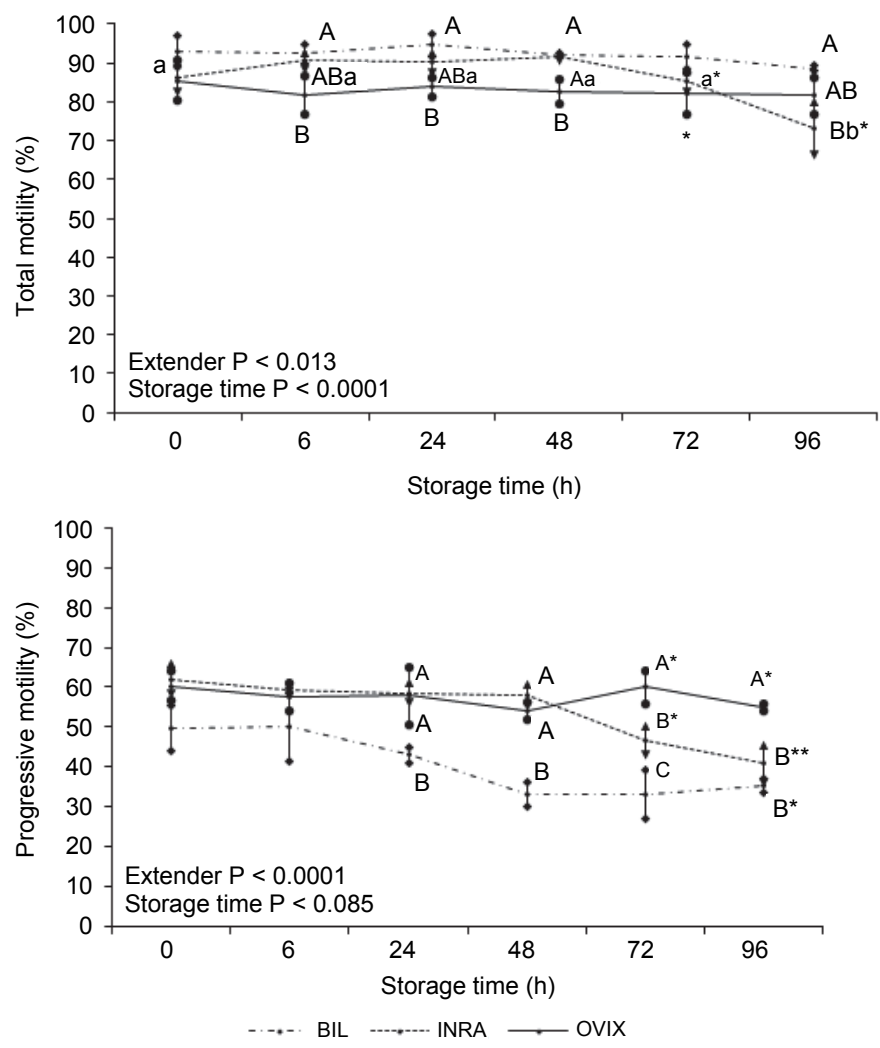

Fig. 1. Effect of extender and storage time on total motility (TM) and progressive motility (PM) in German Mutton Merino semen samples stored at $5{ }^{\circ} \mathrm{C}$. When the interaction between extender and storage time was significant, capital letters (A, B, C) show significant differences between extenders within each time, and small letters $(a, b, c)$ show the effect of time for each extender $(\mathrm{P}<0.05)$. If no interaction was detected, the $\mathrm{P}$ value of the main effect is shown

Differences for TM between extenders were observed at $6 \mathrm{~h}$ of storage. BIL showed significantly higher TM values than OVIX at 6, 24 and $48 \mathrm{~h}$, and similar as INRA, except at $96 \mathrm{~h}$. BIL and OVIX showed similar TM values over the 96-h storage time. In contrast, TM for INRA significantly decreased by $96 \mathrm{~h}$.

BIL showed significantly $(\mathrm{P}<0.05)$ lower PM values than INRA and OVIX at 24 and $48 \mathrm{~h}$. However, OVIX maintained significantly higher values for PM than INRA and BIL during $72 \mathrm{~h}$, with a significant reduction when INRA was used. 


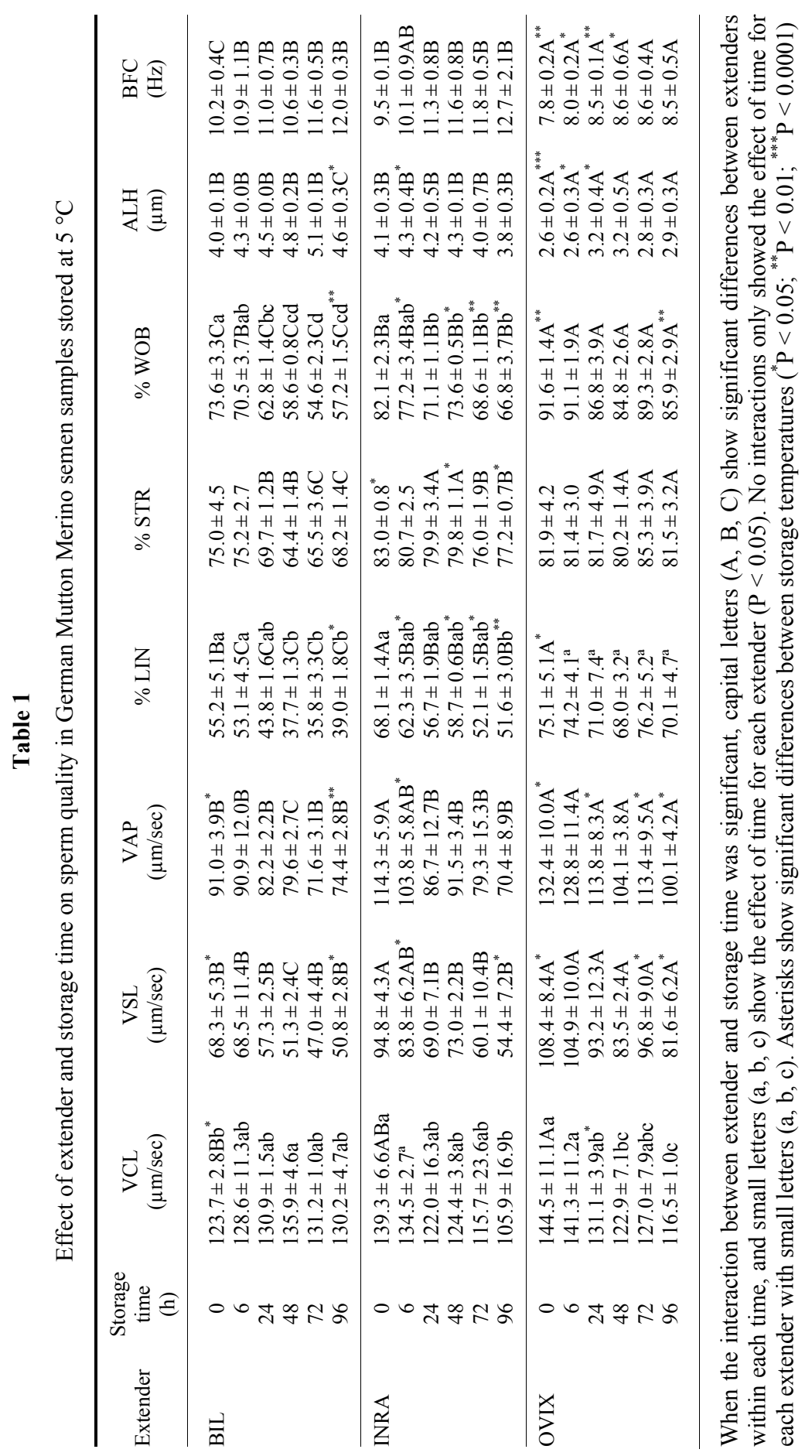


With reference to velocity parameters, VCL at $0 \mathrm{~h}$ was significantly $(\mathrm{P}<$ 0.05) higher for OVIX than BIL, with INRA showing intermediate values. VSL and VAP were significantly higher $(\mathrm{P}<0.01)$ for OVIX throughout the study, in comparison with BIL. INRA also showed significantly lower values, except at 0 and $6 \mathrm{~h}$. It was observed that VCL significantly decreased for OVIX during $48 \mathrm{~h}$, maintained similar values for INRA decreasing at $96 \mathrm{~h}$ compared to $0 \mathrm{~h}$, while in the case of BIL it showed the highest value at $48 \mathrm{~h}$ but practically remained constant throughout the period of storage.

Analysing the trajectory ratio indicators (LIN, STR, WOB), it was observed that OVIX significantly increased LIN values in comparison with INRA and BIL at all studied storage times (except for INRA at $0 \mathrm{~h}$ ). INRA showed significantly higher LIN values than BIL throughout the study. Regarding the effect of time for each extender, LIN did not show significant differences for OVIX; however, BIL induced lower LIN values during $48 \mathrm{~h}$ and INRA showed a slight reduction throughout $96 \mathrm{~h}$.

With reference to STR, significant differences between extenders were observed up to $24 \mathrm{~h}$, with INRA and OVIX showing significantly better STR values than BIL at 24 and $48 \mathrm{~h}$. Up to $72 \mathrm{~h}$ of storage the STR started to significantly decreasing for INRA, while OVIX gave significantly better values. Although STR decreased up to $72 \mathrm{~h}$ of storage in INRA, it maintained significantly higher values than in BIL.

The results of WOB showed significant differences between extenders over $96 \mathrm{~h}$ of storage, OVIX being the extender with the best values, followed by INRA and BIL. At $6 \mathrm{~h}$ of storage, INRA and BIL showed the same WOB values. Considering the effect of time for each extender, WOB significantly decreased for BIL and INRA up to $24 \mathrm{~h}$, and maintained similar values over time for OVIX.

OVIX showed significantly lower ALH and BFC in comparison with BIL and INRA at all studied storage times. Some exceptions were observed for ALH at $96 \mathrm{~h}$, where BIL showed significantly higher values than INRA, and for BFC, where at $6 \mathrm{~h}$ INRA and OVIX showed the same values, and at $0 \mathrm{~h}$ BIL showed significantly higher values than INRA.

\section{Effect of extenders and storage time at $15^{\circ} \mathrm{C}$}

The results showed a trend similar to that observed at $5{ }^{\circ} \mathrm{C}$. Figure 2 shows TM and PM values during different storage times at $15^{\circ} \mathrm{C}$. Significant interactions between extender $\times$ storage time were detected for TM. Other significant interactions were observed for VCL and STR (Table 2). No interactions were found for PM, VSL, VAP, WOB, ALH, and BFC. Therefore, factors were studied as the main effect.

No significant differences were observed between extenders during $48 \mathrm{~h}$ for TM. Nevertheless, TM significantly decreased at $72 \mathrm{~h}$ of storage in samples diluted in INRA in comparison with BIL, with OVIX showing intermediate val- 
ues. BIL showed significant differences for TM at $96 \mathrm{~h}$ in comparison with samples diluted in INRA and OVIX.

Analysing the effect of storage time on TM within the same extender, the results demonstrated that INRA significantly decreased TM during $72 \mathrm{~h}$.
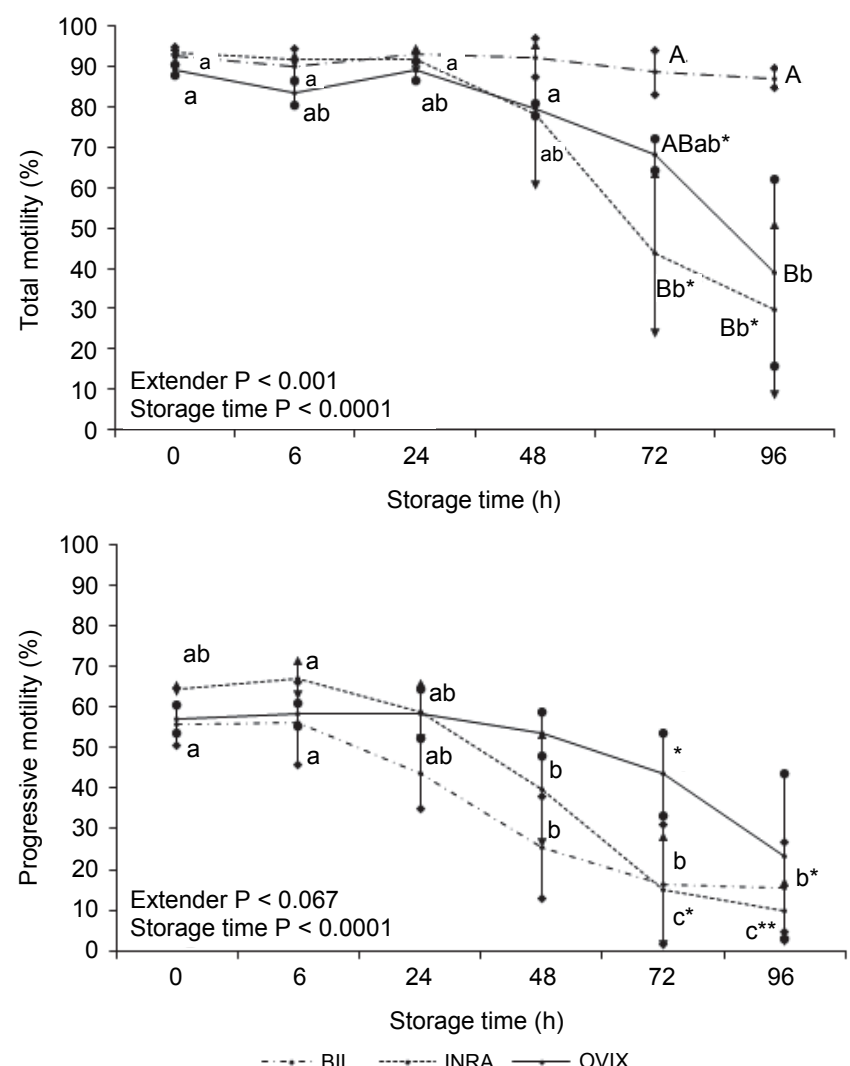

Fig. 2. Effect of extender and storage time on total motility (TM) and progressive motility (PM) in German Mutton Merino semen samples stored at $15^{\circ} \mathrm{C}$. When the interaction between extender and storage time was significant, capital letters $(\mathrm{A}, \mathrm{B}, \mathrm{C})$ show significant differences between extenders within each time, and small letters $(\mathrm{a}, \mathrm{b}, \mathrm{c})$ show the effect of time for each extender $(\mathrm{P}<$ $0.05)$. If no interaction was detected, the $P$ value of the main effect is shown

No differences were found for PM between extenders. Regarding the effect of storage time within the same extender, it was observed that OVIX maintained similar values during $96 \mathrm{~h}$, but this value significantly decreased in samples diluted in BIL for $48 \mathrm{~h}$, and in INRA for $72 \mathrm{~h}$.

OVIX showed significantly higher VCL values at 0 and $6 \mathrm{~h}$ in comparison with BIL, and at $0 \mathrm{~h}$ in comparison with INRA. By contrast, no significant differences between extenders were observed for VCL at 24, 48 and $72 \mathrm{~h}$. Analys- 
ing the effect of storage time on VCL for each extender, no significant differences were observed for BIL during $96 \mathrm{~h}$. However, sperm samples diluted in OVIX showed a significant decrease in VCL during $72 \mathrm{~h}$.

When assessing for VSL, significant differences were detected only at $48 \mathrm{~h}$ of storage, where OVIX showed higher values than BIL. Samples maintained in OVIX showed significantly higher VAP values than INRA and BIL during $48 \mathrm{~h}$ of storage.

No significant differences for LIN were detected between extenders. However, differences were observed for STR during $48 \mathrm{~h}$, where OVIX showed significantly higher values than BIL. In the case of BIL, STR significantly decreased up to $48 \mathrm{~h}$, maintaining similar values during $96 \mathrm{~h}$ of storage for INRA and OVIX. Significant differences between extenders were observed for WOB during $48 \mathrm{~h}$, with OVIX being superior to BIL and INRA.

ALH showed significantly higher values for BIL and INRA than OVIX for $24 \mathrm{~h}$. Furthermore, significant differences between extenders were found at $48 \mathrm{~h}$ for BFC, where INRA showed higher values than BIL and INRA.

\section{Effect of temperature}

The effect of storage temperature $\left(5^{\circ} \mathrm{C}\right.$ or $\left.15^{\circ} \mathrm{C}\right)$ was analysed for each time and only within each extender (Table 1 and 2). For BIL, the only significant differences were observed at $0 \mathrm{~h}$ for VCL, VSL and VAP, being higher in samples maintained at $15^{\circ} \mathrm{C}$, and at $96 \mathrm{~h}$, where PM, VSL, VAP, LIN and WOB showed significantly higher values in samples stored at $5{ }^{\circ} \mathrm{C}$. In contrast, ALH showed significantly lower values in samples maintained at $15^{\circ} \mathrm{C}$.

In the case of INRA, samples maintained at $5^{\circ} \mathrm{C}$ showed significantly higher values for STR at $0 \mathrm{~h}$. Observing the same samples at $6 \mathrm{~h}$ of storage, the tendency was different, VSL, VAP, LIN and WOB being significantly higher in samples maintained at $15^{\circ} \mathrm{C}$. No differences were observed between the two storage temperatures during $24 \mathrm{~h}$. TM and PM showed significantly lower values in samples maintained at $15^{\circ} \mathrm{C}$ for $72 \mathrm{~h}$ in comparison to those maintained at $5^{\circ} \mathrm{C}$. In the same way, the evolution of trajectory ratios (LIN, STR and WOB) over $48 \mathrm{~h}$ showed significantly better results in samples stored at $5{ }^{\circ} \mathrm{C}$ and diluted in INRA.

When the effect of temperature was analysed in samples diluted in OVIX extender, significant differences were observed between temperatures for VSL, VAP, LIN and WOB at $0 \mathrm{~h}$, with samples maintained at $5{ }^{\circ} \mathrm{C}$ showing better results. ALH and BFC were significantly worse in samples stored at $15^{\circ} \mathrm{C}$, both at 6 and $24 \mathrm{~h}$ for ALH, and at 6,24 and $48 \mathrm{~h}$ for BFC. Samples diluted in OVIX at $15^{\circ} \mathrm{C}$ showed significantly higher values at $24 \mathrm{~h}$ for VCL, in contrast to VAP values which were significantly higher when storage was done at $5^{\circ} \mathrm{C}$. At the same time, samples diluted in OVIX and maintained at $5{ }^{\circ} \mathrm{C}$ showed significantly better values for PM, VSL and VAP at 72 and $96 \mathrm{~h}$, and better TM and WOB values (at $72 \mathrm{~h}$ and $96 \mathrm{~h}$, respectively). 


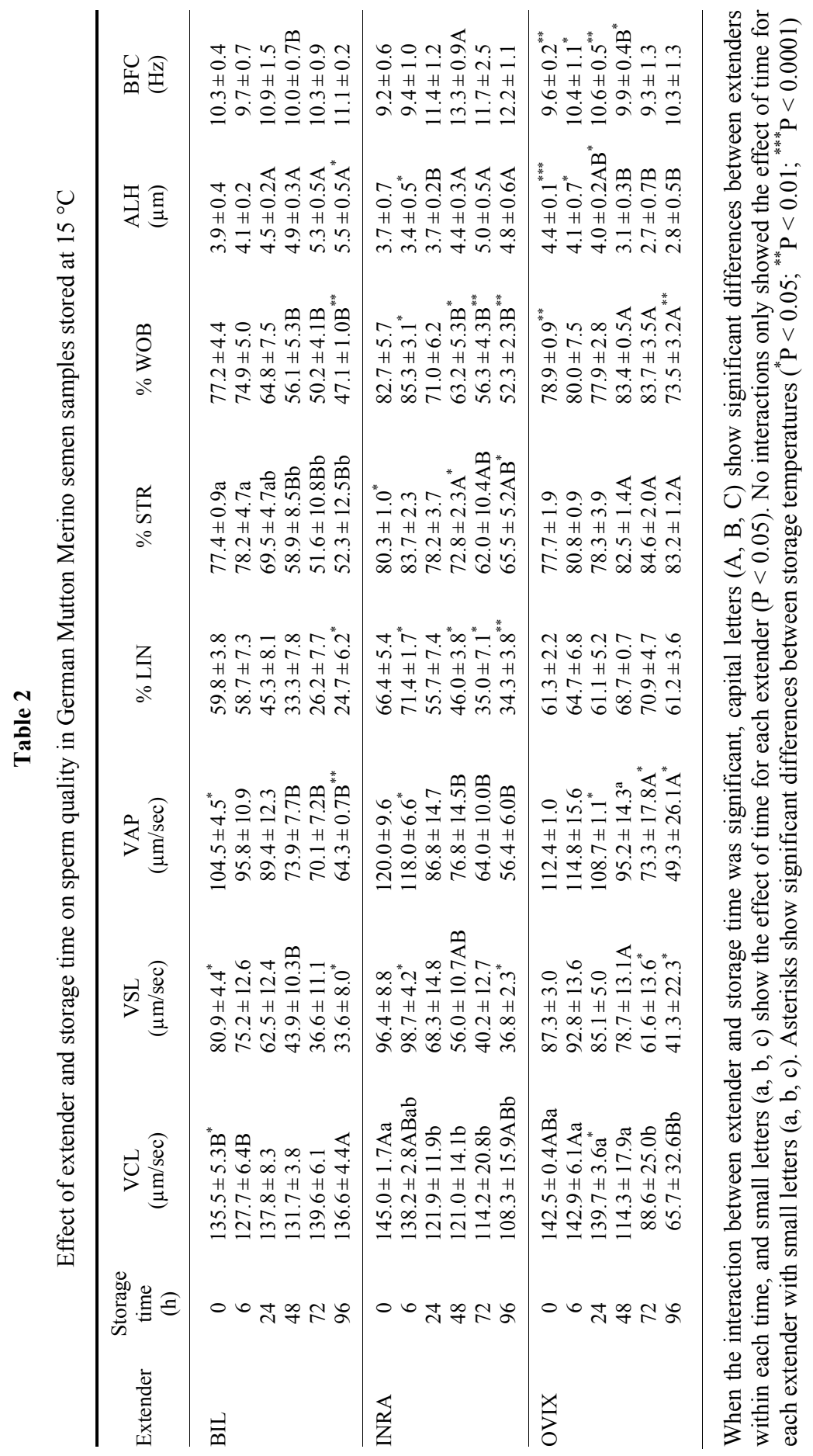




\section{Artificial insemination}

The pregnancy rate was not significantly different between ewes inseminated with sperm samples diluted in INRA or OVIX and maintained at $15{ }^{\circ} \mathrm{C}$, with the pregnancy rate values being $62.6 \%$ and $58.9 \%$, respectively (Table 3 ).

Table 3

Pregnancy rates in ewes after insemination using Segureña semen samples stored at $15^{\circ} \mathrm{C}$

\begin{tabular}{lcc}
\hline Extender & $\begin{array}{c}\text { Number } \\
\text { of inseminated ewes }\end{array}$ & $\begin{array}{c}\text { Pregnancy rate } \\
\text { (number of pregnant ewes) }\end{array}$ \\
\hline INRA & 91 & $62.63 \%(57)$ \\
OVIX & 90 & $58.88 \%(53)$ \\
\hline
\end{tabular}

\section{Discussion}

The storage of ram semen at reduced temperatures $\left(5^{\circ} \mathrm{C}\right.$ or $\left.15{ }^{\circ} \mathrm{C}\right)$ is an interesting alternative for sperm conservation; this is even more so if we consider that cryopreserved ram semen needs laparoscopic intrauterine insemination to achieve acceptable results. Laparoscopic intrauterine insemination is a restrictive and expensive technique and challenging to apply in the field (Álvarez et al., 2012). Different strategies for prolonging the fertile life of spermatozoa include reducing the temperature-induced sperm damage and consequently maintaining their fertilising capacity (Maxwell and Watson, 1996). The present study evaluated the motility characteristics of sperm maintained at $5{ }^{\circ} \mathrm{C}$ and $15^{\circ} \mathrm{C}$ for $96 \mathrm{~h}$, using different commercial extenders, and also determined the pregnancy rate in ewes after cervical insemination with semen samples maintained at $15{ }^{\circ} \mathrm{C}$ for $6-8 \mathrm{~h}$ after collection, according to Anel et al. (2006). Sperm motility is one of the most crucial parameters for sperm quality evaluation, and some studies have been conducted for the standardisation of CASA assessment in the ram (Palacín et al., 2013). Furthermore, it has been observed that the fertilisation capacity of spermatozoa is correlated with the quantitative assessment of sperm motility by CASA. Kasimanickam et al. (2011) suggest that motility is the most meaningful and useful sperm quality indicator, beyond DNA and mitochondrial activity assessment.

The success of liquid storage of ram sperm is associated with a reversible decrease in motility and metabolic activity of sperm obtained by cooling it at low temperatures $\left(5^{\circ} \mathrm{C}\right.$ or $\left.15^{\circ} \mathrm{C}\right)$, linked to the addition of compounds which reduce the production of reactive oxygen species (ROS) (Allai et al., 2015). The growth of ROS concentration is inevitable as a consequence of aerobic conditions where live sperm cells are involved (Agarwal et al., 2005). High ROS concentrations are associated with the inhibition of the normal function of spermatozoa and the reduction of their viability, due to oxidative stress and the subsequent peroxida- 
tion of polyunsaturated fatty acids located in the sperm membranes (Aziz et al., 2004). Lipid peroxidation provokes an irreversible loss of motility, inhibition of fructolysis and respiration, and structural damage of the sperm membrane in ram semen (Dunnett, 1980). This could partially explain the sperm motility (TM and PM) reduction observed over the storage time in samples stored at $15^{\circ} \mathrm{C}$, suggesting that the high metabolism of sperm samples maintained at $15^{\circ} \mathrm{C}$ increases ROS production and, indirectly, reduces the sperm motility.

The extender is an essential factor that was found to affect sperm motility parameters during the present study, and differences between the extenders were demonstrated at both storage temperatures. In semen samples maintained at $5{ }^{\circ} \mathrm{C}$, it was observed that the BIL extender showed similar TM values as the INRA extender, but significantly higher than the OVIX extender between 6 and $48 \mathrm{~h}$. In contrast, PM in samples diluted in OVIX and INRA extenders was higher than in those diluted in BIL from 24 to $72 \mathrm{~h}$. The OVIX extender promoted better PM from 72 and $96 \mathrm{~h}$ than the INRA extender. In contrast, Kasimanickam et al. (2011) did not find any differences during the first $30 \mathrm{~h}$ of storage in the three types of extenders. At the same time, Paulenz et al. (2003) and Quan et al. (2016) reported that Tris egg yolk-based or Tes-based extenders offered better sperm protection properties (motility, membrane functionality, acrosome integrity, and mitochondrial membrane potential) than skimmed milk-based extenders, which is at variance with our results considering the studied variables. In the present study, samples extended in OVIX and maintained at $5{ }^{\circ} \mathrm{C}$ showed slightly higher sperm motility and other kinematic values than those reported by Kasimanickam et al. (2011) and Falchi et al. (2018). Breeds, cooling rates and the software used for motility evaluation could be the reason for the above-mentioned differences (Falchi et al., 2018).

Concerning sperm samples maintained at $15^{\circ} \mathrm{C}$, Mata-Campuzano et al. (2014) suggested that INRA was more efficient to maintain sperm motility than the Tris-based extender (without egg yolk) during $48 \mathrm{~h}$. In our study, the quality of sperm samples stored at $15{ }^{\circ} \mathrm{C}$ decreased over the storage time with particular relevance from $72 \mathrm{~h}$ onward. However, when samples were stored at $5^{\circ} \mathrm{C}$, sperm motility was slightly reduced, probably due to the $\mathrm{pH}$ reduction of the extender. The $\mathrm{pH}$ of ram semen is 6.7-6.8, but during storage sperm samples can be contaminated and bacteria might produce metabolites and reduce extender $\mathrm{pH}$; the consequent reduction of internal spermatic $\mathrm{pH}$ decreases sperm metabolism and motility (Yániz et al., 2011). Regarding the kinematic parameters, OVIX extender at $5{ }^{\circ} \mathrm{C}$ promoted better velocity (except VCL), trajectory (LIN, STR, WOB), ALH and BCF values than INRA and BIL. On the other hand, when samples were stored at $15^{\circ} \mathrm{C}$, VAP, STR, WOB and ALH were higher for the OVIX extender, but significant differences were observed after $24 \mathrm{~h}$. In this sense, numerous studies suggested a correlation of some kinematic parameters with the fertilising ability of spermatozoa. Larsen et al. (2000) observed that VCL was the 
most significant parameter correlated with the fertilisation rate in human sperm. Although VCL values showed significantly better results in the OVIX extender at $15{ }^{\circ} \mathrm{C}$ than in the INRA extender during $6 \mathrm{~h}$ of storage (the same as used for the insemination procedure), no fertility differences were observed during the insemination trial. Sanchez-Partida et al. (1999) reported that VCL, VSL, VAP and ALH are positively correlated with fertility after intrauterine insemination. Similarly, Robayo et al. (2008) suggested that VAP and VCL are good predictors of the ability of spermatozoa to migrate in the cervical mucus of ewes. In other species, kinematic parameters are also positively correlated with litter size in boar (Holt et al., 1997) and with fertility in buffalo (Hussain et al., 2016).

The most efficient method to yield acceptable pregnancy rates was the application of cervical insemination with semen preserved at $15^{\circ} \mathrm{C}$ and for $6-8 \mathrm{~h}$ post-collection (Anel et al., 2006). O'Hara et al. (2010) suggested that the fertilising capacity was greater at $6 \mathrm{~h}$ and $24 \mathrm{~h}$ if sperm was stored at $15^{\circ} \mathrm{C}$; in vitro fertilisation trials were used to test the validity of this proposal. Our results show no significant differences in pregnancy rate between INRA (62.6\%) and OVIX $(58.9 \%)$ extenders after application of cervical insemination with semen preserved at $15{ }^{\circ} \mathrm{C}$ around $6 \mathrm{~h}$ post-collection. These results using skimmed milkbased extender (INRA) in rams are in accordance with those obtained by Paulenz et al. (2003) who reported a $66 \%$ non-return rate and $61 \%$ lambing rate using cooled liquid semen. Similarly, Roostaei-Ali Mehr et al. (2013) obtained 56\% lambing rate when sperm samples were diluted with skimmed milk-based extender and incubated for $52 \mathrm{~h}$ at $5^{\circ} \mathrm{C}$.

In conclusion, liquid storage at $5{ }^{\circ} \mathrm{C}$ could be an alternative for sperm storage, OVIX extender being the most interesting option for ram sperm dilution. Since it provides similar in vitro and in vivo efficacy as the other extenders, it can be a good replacement for extenders of animal origin, in order to avoid the potential dissemination of diseases.

\section{Acknowledgements}

The authors wish to acknowledge the technical staff at Diputacion de Cordoba, Spain, for ram management and semen collection, and also the Asociacion Nacional de Criadores de Ovino Segureño (ANCOS) for ram transfer.

\section{References}

Agarwal, A. and Prabakaran, S. A. (2005): Oxidative stress and antioxidants in male infertility: a difficult balance. Iran J. Reprod. Med. 3, 1-8.

Allai, L., Druart, X., Contell, J., Louanjli, N., Moula, A. B., Badi, A., Essamadi, A., Nasser, B. and El Amiri, B. (2015): Effect of argan oil on liquid storage of ram semen in Tris or skim milk based extenders. Anim. Reprod. Sci. 160, 57-67. 
Álvarez, M., Tamayo-Canul, J., Anel, E., Boixo, J. C., Mata-Campuzano, M., Martínez-Pastor, F., Anel, L. and de Paz, P. (2012): Sperm concentration at freezing affects post-thaw quality and fertility of ram semen. Theriogenology 77, 1111-1118.

Anel, L., Álvarez, M., Martinez-Pastor, F., Garcia-Macias, V., Anel, E. and de Paz, P. (2006): Improvement strategies in ovine artificial insemination. Reprod. Dom. Anim. 41, 30-42.

Anel, L., Kaabi, M., Abroug, B., Álvarez, M., Anel, E., Boixo, J. C., de la Fuente, L. F. and de Paz, P. (2005): Factors influencing the success of vaginal and laparoscopic artificial insemination in churra ewes: a field assay. Theriogenology 63, 1235-1247.

Aziz, N., Saleh, R. A., Sharma, R. K., Lewis-Jones, I., Esfandiari, N., Thomas, A. J. and Agarwal, A. (2004): Novel association between sperm reactive oxygen species production, sperm morphological defects, and the sperm deformity index. Fertil. Steril. 81, 349-354.

Chelucci, S., Pasciu, V., Succus, S., Addis, D., Leoni, G. G., Manca, M. E., Naitana, S. and Berlinguer, F. (2015): Soybean lecithin-based extender preserves spermatozoa membrane integrity and fertilizing potential during goat semen cryopreservation. Theriogenology 83, 1064-1074.

Dunnett, C. W. (1980): Pairwise multiple comparisons in the homogeneous variance, unequal sample size case. J. Am. Statistical Assoc. 75, 789-795.

Falchi, L., Galleri, G., Zedda, M. T., Pau, S., Bogliolo, L., Ariu, F. and Ledda, S. (2018): Liquid storage of ram semen for $96 \mathrm{~h}$ : Effects on kinematic parameters, membranes and DNA integrity, and ROS production. Livest. Sci. 207, 1-6.

Halbert, G. W., Dobson, H., Walton, J. S. and Buckrell, B. C. (1990): The structure of the cervical canal of the ewe. Theriogenology 33, 977-992.

Holt, C., Holt, W. V., Moore, H. D. M., Hugh, R. C. B. and Curnock, R. M. (1997): Objectively measured boar sperm motility parameters correlate with the outcomes of on-farm inseminations: results of two fertility trials. J. Androl. 18, 312-323.

Hussain, A., Murtaza, S. H. A. and Sarwat, J. (2016): Semen quality parameters as fertility predictors of water buffalo bull spermatozoa during low-breeding season. Theriogenology 86, $1516-1522$.

Kasimanickam, R., Kasimanickam, V., Tibary, A. and Pelzera, K. (2011): Effect of semen extenders on sperm parameters of ram semen during liquid storage at $4{ }^{\circ} \mathrm{C}$. Small Rumin. Res. 99, 208-213.

Larsen, L., Scheike, T., Jensen, T. K., Bonde, J. P., Ernst, E. and Hjollund, N. H. (2000): Computer-assisted semen analysis parameters as predictors for fertility of men from the general population. The Danish First Pregnancy Planner Study Team. Hum. Reprod. 15, 1562-1567.

López, A., Söderquist, L. and Rodríguez-Martinez, H. (1999): Sperm viability in ram semen diluted and stored in three different extenders. Acta Vet. Scand. 40, 1-9.

Lupi, T. M., Nogales, S., León, J. M., Barba, C. and Delgado, J. V. (2015): Characterization of commercial and biological growth curves in the Segureña sheep breed. Animal 9, 1341-1348.

Mata-Campuzano, M., Álvarez-Rodríguez, M., Tamayo-Canul, J., López-Urueña, E., de Paz, P., Anel, L., Martínez-Pastor, F. and Álvarez, M. (2014): Refrigerated storage of ram sperm in presence of Trolox and GSH antioxidants: Effect of temperature, extender and storage time. Anim. Reprod. Sci. 151, 137-147.

Maxwell, W. M. C. and Watson, P. F. (1996): Recent progress in the preservation of ram semen. Anim. Reprod. Sci. 42, 55-65.

O’Hara, L., Hanrahan, J. P., Richardson, L., Donovan, A., Fair, S., Evans, A. C. and Lonergan, P. (2010): Effect of storage duration, storage temperature, and diluent on the viability and fertility of fresh ram sperm. Theriogenology 73, 541-549.

Palacín, I., Vicente-Fiel, S., Santolaria, P. and Yániz, J. L. (2013): Standardization of CASA sperm motility assessment in the ram. Small Rum. Res. 112, 128-135.

Paulenz, H., Söderquist, L., Ådnøy, T., Fossen, O. H. and Andersen, K. (2003): Effect of milk-and TRIS-based extenders on the fertility of sheep inseminated vaginally once or twice with liquid semen. Theriogenology 60, 759-766. 
Quan, G. B., Wu, G. Q., Wang, Y. J., Li, D. J., Ma, Y. and Hong, Q. H. (2016): Effects of the Tris, Tes, or skim milk based extender on in vitro parameters of ram spermatozoa during liquid storage. Small Rumin. Res. 134, 14-21.

Robayo, I., Montenegro, V., Valdés, C. and Cox, J. F. (2008): CASA assessment of kinematic parameters of ram spermatozoa and their relationship to migration efficiency in ruminant cervical mucus. Reprod. Dom. Anim. 43, 393-399.

Roostaei-Ali Mehr, M., Chambary, B. and Hossein-Zadeh, N. G. (2013): Effect of different diluents and storage time on field fertility of cooled ram semen after vaginal insemination. Small Rumin. Res. 115, 82-85.

Salamon, S. and Maxwell, W. M. C. (2000): Storage of ram semen. Anim. Reprod. Sci. 62, 77-111.

Sanchez-Partida, L. G., Windsor, D. P., Eppleston, J., Setchell, B. P. and Maxwell, W. M. C. (1999): Fertility and its relationship to motility characteristics of spermatozoa in ewes after cervi$\mathrm{cal}$, transcervical, and intrauterine insemination with frozen-thawed ram semen. J. Androl. 20, 280-288.

Tabárez, A., Garcia, W. and Palomo, M. J. (2017): Effect of the type of egg yolk, removal of seminal plasma and donor age on buck sperm cryopreservation. Small Rumin. Res. 149, 91-98.

Toker, M. B., Alcay, S., Gokce, E. and Ustuner, B. (2016): Cryopreservation of ram semen with antioxidant supplemented soybean lecithin-based extenders and impacts on incubation resilience. Cryobiology 72, 205-209.

Yániz, J. L., Mateos, J. A. and Santolaria, P. (2011): Zwitterionic buffers preserve ram semen quality more efficiently than TRIS during storage at $15^{\circ} \mathrm{C}$. Small Rumin. Res. 95, 54-60. 